\title{
Men's mental health: Connection to urologic health
}

\author{
Andrew Matthew, PhD; ${ }^{*}$ Dean Elterman, $M D^{+}$ \\ "Psychologist, Princess Margaret Cancer Centre, Department of Surgical Oncology, Division of Urology, Toronto, ON; +Urologist, Toronto Western Hospital, Division of Urology, Toronto, ON
}

Cite as: Can Urol Assoc J 2014;8(7-8):S153-5. http://dx.doi.org/10.5489/cuaj.2312

Published online August 11, 2014.

\section{Abstract}

Historically, the specialty of urology has focused on single-system diseases. In recent years, however, there has been increasing recognition of the interconnectivity between the various systems, such as cardiovascular disease, metabolic syndrome, erectile dysfunction and prostate cancer. This constellation of disease/syndrome and dysfunction may place urologists at the centre of men's overall health concerns. As urologists considering taking on a leadership role in men's health, they should also consider their potential in helping men suffering from the significant burden of a mental health disorder. Urologists may have a unique opportunity to identify mental health issues in their male patients, influence healthy behaviour change, and successfully refer men, who might otherwise not seek help, to appropriate medical/ psychological care.

\section{Men's mental health}

An estimated 3.4 million Canadian men are currently living with mental illness. ${ }^{1}$ This number is likely an underestimation given that a large proportion of men experiencing symptoms of mental illness do not seek the help of a professional. ${ }^{2-4}$ This gap in care has grave outcomes as Canadian men are at least 3 times more likely to die by suicide than Canadian women ${ }^{5}$ - a figure that increases to 7 times among elderly men. ${ }^{6}$ Specific to urologic diseases/disorders, such as urologic cancers, lower urinary tract symptoms and erectile dysfunction (ED), men experience elevated levels of anxiety and depression., ${ }^{7,8}$ For example, the risk of suicide in men with prostate cancer is over 4 times that of a similarly aged man without prostate cancer. ${ }^{9}$ Patients with lower urinary tract symptoms (LUTS) experience elevated levels of psychosocial distress, with depression rates of $6 \%$ to $21 \%$ and anxiety rates of $3 \%$ to $10 \% .{ }^{10}$ An estimated $10 \%$ of men with ED suffer from depression, and $2.5 \%$ to $37 \%$ suffer from anxiety. ${ }^{11}$ Given the relationship between mental health and overall health-related quality of life, it is clear that increasing numbers of men in general, and men with urologic disease, are suffering a significant burden and that most of this burden remains untreated by healthcare professionals.

Barriers to accessing mental health services include stigma, differences in expression of emotional problems (compared to women), maladaptive coping, and lack of awareness of support services in the community.

\section{Stigma}

Results suggest that the most prominent barrier to seeking and accessing mental health services is stigma. ${ }^{12,13}$ Seeking mental healthcare services remains a secretive and shameful activity for many individuals. ${ }^{14}$ The anticipation of social consequences and discrimination is often enough to force men into silence. While mental health stigma is not exclusively a male issue, men face a disproportionate amount of stigma, which is often perpetuated by masculine ideals of strength and self-reliance. A firm belief in stoicism and the need to control emotions may lead some men with anxiety and depression to perceive emotional distress as shameful, and hide their symptoms from others. ${ }^{13,15}$

\section{Differences in expression of emotional problems}

Another factor that may complicate seeking help involves the recognition that men's experience of mental illness may differ from that of women. ${ }^{16}$ For example, men are more likely to manifest depression as anger, aggression and violent behaviour rather than sad affect. ${ }^{17}$ Instead of exhibiting the traditionally viewed symptoms of depression, such as lack of sleep, energy and interest in activities, men often put on a tough exterior to mask their distress. Consequently, men may struggle recognizing symptoms as originating from a mental health condition. In fact, a recognized limitation of current epidemiologic estimates for mood disorders, such as depression, is that the estimates tend to miss the symptoms most frequently experienced by 
men. ${ }^{18}$ Even in the primary care setting, men with mild depressive symptoms are more likely to be misdiagnosed than women, particularly when evaluated by male practitioners. ${ }^{19}$ In instances where symptoms are appropriately interpreted, men may experience denial or under-evaluate their symptoms. ${ }^{20}$ Such responses may cause men to avoid treatment, believe that the issue will go away on its own, or think that their symptoms are not serious enough to warrant professional attention. Similarly, men may also be concerned that the healthcare practitioner might think less of them for asking for help or believe that professional assistance will not be able to help with their concerns. ${ }^{12,20,21}$

\section{Maladaptive coping}

Unfortunately, this initial idealized masculine response to mental health problems can evolve over time into adverse coping behaviours. ${ }^{22}$ When faced with the choice of seeking help and the perceived change in masculine identity, men are more likely to self-medicate with illicit drugs, abuse alcohol, work excessively or participate in infidelity. ${ }^{18}$ This manifestation of emotional repression is deemed by the man as more socially acceptable than traditional characteristics of depression. ${ }^{23}$ However, when these maladaptive coping mechanisms eventually fail, men are at risk for violence or severe self-harming behaviour that may involve suicide.

\section{Lack of awareness of support services}

Finally, logistical barriers may prevent men from accessing mental health care. For example, not knowing which services are available, not knowing how to access services and lacking transportation to reach the service may all serve as barriers. ${ }^{24}$

\section{The role of the urologist in men's mental health}

Given the interconnectivity of the various health issues that often confront men, it is important for urologists to recognize their role in directly or indirectly (via referral) assisting men with a wide variety of health issues, such as cardiovascular disease, metabolic syndrome, ED and prostate cancer. If urologists are to consider taking on a leadership role in men's health, they should also consider their potential role in helping men who are suffering from the significant burden of a mental health disorder. For many men, visits to the urologist may be the first regular contact they have with health care over many years of their lifespan. This provides a unique opportunity for the urologist to identify men experiencing mental health problems, and encourage these men to engage in healthy behaviour and/or access mental healthcare services. In this regard, urologists should not underestimate their influence. In examining those who carried the greatest influence in men seeking mental health support, Cusack and colleagues concluded: "that intimate partners and
GPs or other health professionals were the most frequent and strongest sources of influence. ${ }^{\prime 25}$

Helping patients with mental health problems is not entirely unfamiliar territory for most urologists. For example, for the patient with urological cancer, the urologist may take on the role of screening for signs of distress, providing education on their diagnosis, treatment and related-side effects, and offering support through referral to psychosocial services or specific rehabilitation programming. For men suffering from LUTS, the urologist may perform a functional analysis to determine the impact of symptoms on daily life, offer practical solutions (e.g., Kegel exercises), and provide psychosocial referrals to address issues related to self-esteem or interpersonal relationships. Finally, for patients suffering from ED it is generally recognized by the urologist that a biopsychosocial approach is needed that goes beyond the prescription of pro-erectile agents to include counselling on models of incorporating pro-erectile agents into regular sexual activity.

Accordingly, the urologist may expand his or her role in screening for signs of distress (identification), influencing behaviour change, and facilitating medical and psychological care, beyond that directly associated with urologic disease. Common presentations of mental health disorder in men include substance or alcohol abuse, marriage/couples troubles, work stresses or work/life imbalances, or adjustment to major lifestyle changes, such as retirement. Distress screening (e.g., Patient Health Questionnaire-9 ${ }^{26}$ and brief questions regarding relevant life domains (e.g., work, relationship, substance use, sexual function) may help to identify men suffering from mental health problems. Similarly, urologists may help patients engage in behaviour change through their influential role as healthcare professionals. The patient's visit to the urologist's office may present an opportunity for a "teachable moment" 27 that can serve to motivate healthy behaviour change that could include something as specific as smoking cessation to something as broad as seeking help from a mental health professional. The relationship between the urologist and the patient through regular visits may also serve to help normalize mental health issues and combat stigma. The urologist can then act as a gateway to healthcare services through appropriate referrals. Through this early and regular clinical contact with male patients, the urologist with the general practitioner may play an important role in risk reduction, prevention and management of the potential burden of mental illness.

In taking a page from the experiences of general practitioners working with their patients who suffer from mental illness, increased knowledge and training in mental health can go a long way (e.g., fundamental training in distress screening, healthbehaviour change models and motivational interviewing). Richards and colleagues examined the attitudes of general practitioners toward depression, as well as their confidence in being able to assess and treat depression. They found that general practitioners who had training in mental health were 
more positive in their attitudes toward depression and helping their depressed patients. General practitioners without mental health training reported insufficient knowledge about depression as a barrier to managing patients and their treatments. ${ }^{28}$ For urologists interested in advocating for men's overall health, training in mental health could be offered online or through workshops at provincial and national meetings or conferences.

\section{Conclusion}

Following a similar model of gynecology in women's health, urologists are positioned to offer a gender-specific approach to the health service delivery, government policy, research and advocacy. As urologists consider taking on a leadership role in men's health, they will need to consider their potential in helping men with a mental health disorder. Urologists may have a unique opportunity to identify mental health issues in their male patients, influence healthy behaviour change, and successfully refer men, who might otherwise not seek help, to appropriate medical/psychological care. By taking on a leadership role in men's health, urologists have the potential to influence the lives of many men suffering from mental health problems through risk reduction and preventive measures.

Competing interests: Dr. Matthew and Dr. Elterman declare no competing financial or personal interests.

\section{References}

1. The Canadian Mental Health Association Supports the First-Ever National Men's Health Week [press release]. Ottawa, ON: Canadian Mental Health Association; June 10, 2014. http://www.cmha.ca/news/the-canadianmental-health-association-supports-he-first-ever-national-mens-health-week/\#.U7LblkCZi-E. Accessed July 22, 2014.

2. Results from the 2010 National Survey on Drug Use and Health: Mental Health Findings. Rockville, MD: Substance Abuse and Mental Health Services Administration; 2012.

3. Maier $W$, Gansicke $M$, Gater $R$, et al. Gender differences in the prevalence of depression: A survey in primary care. J Affective Disorders 1999;53:241-52. http://dx.doi.org/10.1016/S0165-0327(98)00131-1

4. Rickwood DJ, Braithwaite VA. Social-psychological factors affecting help-seeking for emotional problems. Soc Sci Med 1994;39:563-72. hittp://dx.doi.org/10.1016/0277-9536(94)90099-X

5. Navaneelan T. Suicide rates: An overview. Statistics Canada Catalogue no. 82-624-X. 2012. http://www. statcan.gc.ca/pub/82-624-x/2012001/article/11696-eng.htm. Accessed July 7, 2014.

6. Hee Ahn M, Park S, Ha K, et al. Gender ratio comparisons of the suicide rates and methods in Korea, Japan, Australia, and the United States. J Affect Disord 2012;142:161-5. http://dx.doi.org/10.1016/i. jad.2012.05.008

7. Barczak $P$, Kane $N$, Andrews $S$, et al. Patterns of psychiatric morbidity in a genito-urinary clinic. A validation of the Hospital Anxiety Depression scale (HAD). Br J Psychiatry 1988;152:698-700. http://dx.doi. org/10.1192/bip.152.5.698
8. Seivewright $\mathrm{H}$, Salkovskis $\mathrm{P}$, Green J, et al. Prevalence and service implications of health anxiety in genitourinary medicine clinics. Int J STD AIDS 2004;15:519-22. http://dx.doi.org/10.1258/0956462041558122

9. Llorente MD, Burke M, Gregory GR, et al. Prostate cancer: A significant risk factor for late-life suicide. Am I Geriatr Psychiatry 2005;13:195-201. http://dx.doi.org/10.1097/00019442-200503000-00004

10. Pinto JDO, He HG, Chan SWC, et al. Health related quality of life and psychological well being in patients with benign prostatic hyperplasia. J Clin Nursing 2014 May 22. [Epub ahead of print]. http://dx.doi.org/10.1111/ jocn. 12636

11. Corretti G, Baldi I. The relationship between anxiety disorders and sexual dysfunction. Psychiatric Times 2007:24:9

12. Gulliver A, Griffiths $K M$, Christensen H. Perceived barriers and facilitators to mental health help-seeking in young people: A systematic review. BMC Psychiatry 2010;10:113. http://dx.doi.org/10.1186/1471-244X-10-113

13. Cook TM, Wang J. Descriptive epidemiology of stigma against depression in a general population sample in Alberta. BMC Psychiatry 2010;10:29. http://dx.doi.org/10.1186/1471-244X-10-29

14. Aromaa E, Tolvanen A, Tuulari J, et al. Predictors of stigmatizing attitudes towards people with mental disorders in a general population in Finland. Nordic J Psychiatry 2011;65:125-32. http://dx.doi.org/10.3109/08 039488.2010 .510206

15. Magovcevic M, Addis ME. Linking gender-role conflict to nonnormative and self-stigmatizing perceptions of alcohol abuse and depression. Psychol Men Masc 2005;6:127-36. http://dx.doi.org/10.1037/1524-9220.6.2.127

16. Kuehn BM. Men face barriers to mental health care. JAMA 2006;296:2303-4. http://dx.doi.org/10.1001/ jama.296.19.2303

17. Brownhill S, Wilhelm K, Barclay L, et al. 'Big build': hidden depression in men. Aust NZ I Psychiatry 2005:39:921-31.

18. Moller-Leimkuhler AM. Barriers to help-seeking by men: A review of sociocultural and clinical literature with particular reference to depression. J Affect Disord 2002;71:1-9. http://dx.doi.org/10.1016/S0165$0327(01) 00379-2$

19. Stoppe G, Sandholzer H, Huppertz C, et al. Gender differences in the recognition of depression in old age. Maturitas 1999:32:205-12. http://dx.doi.org/10.1016/S0378-5122(99)00024-9

20. Mansfield AK, Addis ME, Courtenay W. Measurement of men's help seeking: Development and evaluation of the barriers to help seeking scale. Psychol Men Masc 2005;6:95-108. http://dx.doi.org/10.1037/15249220.6.2.95

21. Pepin R, Segal DL, Coolidge FL. Intrinsic and extrinsic barriers to mental health care among community-dwelling younger and older adults. Aging Ment Health 2009;13:769-77. http://dx.doi. org/10.1080/13607860902918231

22. Oliffe IL, Galdas PM, Han CS, et al. Faux masculinities among college men who experience depression. Health (London) 2013;17:75-92. http://dx.doi.org/10.1177/1363459312447256

23. Wilhelm KA. Men and depression. Aust Fam Physician 2009;38:102-5.

24. Stefl ME, Prosperi DC. Barriers to mental health service utilization. Community Men Health J 1985;21:167-78. http://dx.doi.org/10.1007/BF00754732

25. Cusack J, Deane FP, Wllson CJ, et al. Who influence men to go to therapy? Reports from men attending psychological services. Int JAdv Couns 2004;26:271-83. http://dx.doi.org/10.1023/B:ADC0.0000035530.44111.08

26. Martin A, Rief W, Klaiberg A, et al. Validity of the brief patient health questionnaire mood scale (PHQ-9) in the general population. Gen Hosp Psychiatry 2006;28:71-7. http://dx.doi.org/10.1016/i.genhosppsych.2005.07.003

27. Bassett JC, Gore JL, Chi AC, et al. Impact of a bladder cancer diagnosis on smoking behavior. J Clin Oncol 2012;30:1871-8. http://dx.doi.org/10.1200/JC0.2011.36.6518

28. Richards JC, Ryan P, McCabe MP, et al. Barriers to the effective management of depression in general practice. Aust N Z J Psychiatry 2004;38:795-803. http://dx.doi.org/10.1080/i.1440-1614.2004.01464.x

Correspondence: Dr. Dean Elterman, Toronto Western Hospital, 399 Bathurst St, Toronto, ON M5T 2S8; deanelterman@gmail.com 